\title{
ENTRE O SOCIAL E BIOLÓGICO: REPENSANDO A MATERNIDADE À LUZ DAS NOVAS TÉCNICAS DE REPRODUÇÃO ASSISTIDA
}

\author{
Cláudia Álvares
}

\begin{abstract}
RESUMO
Os progressos científicos na área das biotecnologias permitem uma crescente dissociação das componentes social e biológica da parentalidade, com o discurso médico a procurar enquadrar, na maior parte das vezes, o social no âmbito do biológico por forma a não pôr em causa definições consensuais de parentalidade, particularmente no que toca ao entendimento do conceito de 'maternidade'. Este enquadramento do social no seio do biológico é visível no modo como as técnicas de procriação assistida são frequentemente descritas na imprensa como simulando um processo biológico 'natural', naturalidade essa que a patologia da infertilidade impede de tomar o seu livre curso. Este artigo pretende analisar os entendimentos diferenciados e por vezes contraditórios do conceito de maternidade que ressaltam da cobertura noticiosa da Procriação Medicamente Assistida por parte do Jornal Público nos anos 2008 e 2009 . O corpus analítico demonstra que ao privilegiar o discurso médico na interpretação hegemónica dos riscos e benefícios dessas técnicas de reprodução, o Público veicula uma concepção da maternidade que privilegia claramente o biológico em detrimento do social: a transmissão de um património genético é tida como o factor mais importante no que toca à definição de maternidade, sendo que se sobrepõe à dimensão de 'educar/criar um filho'.
\end{abstract}

\section{Palavras-Chave}

Procriação medicamente assistida; maternidade; infertilidade; identidade feminina; imprensa; discurso médico

\section{INTRODUÇÃO}

$\mathrm{O}$ artigo $4^{\circ}$ da lei . $^{\circ}$ 32/2006, que regula a Procriação Medicamente Assistida em Portugal (PMA), define as técnicas de PMA como 'método subsidiário, e não alternativo, de procriação', cuja utilização 'só pode verificar-se mediante diagnóstico de infertilidade.' A infertilidade é considerada uma patologia que pode ser alvo de 'cura' mediante técnicas médicas que simulem os processos reprodutivos 'naturais'. Entre estas técnicas encontram-se a inseminação intra-uterina, a indução ovárica, a fertilização in vitro e a injecção intracitoplasmática de espermatozóides.

Os progressos científicos na área das biotecnologias permitem uma crescente dissociação das componentes social e biológica da parentalidade, com o discurso médico a procurar enquadrar, na maior parte das vezes, o social no âmbito do biológico por forma a não pôr em causa definições consensuais de parentalidade, particularmente no que toca ao entendimento do conceito de 'maternidade'. Este enquadramento do social no seio do biológico é visível no modo como as técnicas de procriação assistida são frequentemente descritas como simulando um processo biológico 'natural', naturalidade essa que a patologia da infertilidade impede de tomar o seu livre curso. 
No entanto, apesar das múltiplas tentativas de contextualização, por parte da classe médica, dos novos entendimentos possíveis do conceito de maternidade no âmbito de um discurso que privilegia o 'biológico' ou a 'natureza', o progresso alucinante da técnica faz com que o fosso entre o social e o biológico se torne cada vez mais visível a olho nu. Essa discrepância entre polaridades que giram em torno do binómio 'natureza' Vs. 'cultura' tem múltiplas implicações ao nível daquilo que até há pouco tempo consistia num conceito de definição relativamente consensual, o de 'maternidade'. A instabilização da 'maternidade' também põe em causa outros conceitos que lhe estão tangencialmente ligados, nomeadamente os de género, sexo, orientação sexual, saúde, classe social e mesmo nacionalidade/etnia.

Este artigo pretende analisar os entendimentos diferenciados e por vezes contraditórios do conceito de maternidade que ressaltam da cobertura noticiosa da Procriação Medicamente Assistida por parte do Jornal Público nos anos 2008 e 2009.'

\section{INFERTILIDADE FEMININA}

A infertilidade feminina é difícil de definir de modo taxativo porque, a partir da menopausa, pode ser entendida como um processo 'natural' fisiológico e não patológico. Por isso mesmo, o discurso médico procura articular consensos relativamente àquilo que entende como processos fisiológicos naturais e os seus desvios. No entanto, se entendermos a infertilidade como 'uma incapacidade de concepção ou de levar a gravidez até ao fim', interpretação de Mário Sousa, director do Instituto de Ciências Biomédicas Abel Salazar (ICBAS), então mesmo uma mulher menopáusica pode ser considerada infértil e uma potencial 'beneficiária do tratamento' (Faria, 11.07.2008).

Apesar da lei portuguesa não estabelecer limite máximo de idade para a Procriação Medicamente Assistida, a idade é a variável mais frequentemente referida como factor dissuasor no tratamento da infertilidade. Habitualmente, o limite de faixa etária para aplicação de qualquer técnica que envolva os ovócitos da mulher em Portugal ronda os 45 anos; porém, no caso de doação de ovócitos, esse limite é estendido até aos 50 anos. Alberto Barros, fundador do Centro de Genética da Reprodução, afirma o seguinte: 'A lei portuguesa não impõe limites etários, mas pressupõe-se que estes são a idade para procriar. A partir dos 50 anos, não se justifica estar a investir, até porque a maior parte das experiências estão condenadas ao fracasso' (Faria, 11.07.2008). Em Inglaterra, o limite de acesso às técnicas de fertilização in vitro costuma ser os 55 anos. Tal situação implica que pacientes que tenham atingido esse limite se desloquem a outros países, tais como os EUA ou a Espanha, onde não existe esse limite de idade para a aplicação de técnicas de Procriação Medicamente Assistida (PMA) (Gerschenfeld, 02.07.2008).

Efectivamente, os media contribuem para a criação do mito de que é fácil engravidar depois dos 40: 'Se a Madonna pôde ser mãe aos 41, a Cherie Blair aos 45, a Susan

\footnotetext{
' Originalmente redigido no âmbito de um projecto mais alargado intitulado 'As Mulheres e o Espaço Público: O Papel dos Media em Áreas Prioritárias da Plataforma de Acção de Pequim' (PTDC/CCl/67146/2006), coordenado por Maria João Silveirinha, o presente artigo recorreu aos artigos jornalísticos recolhidos nesse contexto específico, não versando quaisquer alterações legislativas introduzidas em período posterior.
} 
Sarandon aos 46, a Beverly d'Angelo aos 49, porque é que nós também não podemos?' (Machado, 24.03.2008). A par das biografias das estrelas de Hollywood, também surgem notícias de mulheres que conseguiram engravidar na casa dos 60 , até mesmo 70 , anos: uma romena de 66 anos, seguida de uma espanhola de 67 anos e, mais recentemente, uma indiana de 70 anos engravidaram mediante recurso às novas tecnologias de reprodução assistida (Faria, 11.07.2008). Tais episódios correm o risco de contribuir para a "ideia de uma falsa longevidade reprodutiva" (Alberto Barros citado em Machado, 24.03.2008), obscurecendo-se o facto de tanto umas como outras terem recorrido a técnicas de Procriação Medicamente Assistida, nomeadamente à doação de ovúlos. O discurso médico veiculado nas notícias sobre o assunto revela um tom censório: a longevidade reprodutiva não é natural, mas antes resultado da aplicação de técnicas artificiais, o que pode incorrer em perigo por exponenciar a ilusão de que o ser humano possa controlar o mundo circundante. Outro exemplo citado consiste na congelação de ovócitos para utilização futura, técnica essa que permite à mulher adiar a maternidade. Embora o leitor não seja informado da razão precisa pela qual tais 'avanços científicos e técnicos' constituam 'aparentes panaceias' (Silva Costa, 08.03.2008), essa congelação é apontada como algo a evitar, como se houvesse um consenso tácito em torno de idades aceitáveis e não-aceitáveis para se ser mãe. Essa aceitabilidade está intrinsecamente ligada àquilo que socialmente se considera como 'natural' e 'anti-natura', conotando um conceito de maternidade biologicamente definido.

A lei portuguesa que regulamenta a Procriação Medicamente Assistida impõe que tais técnicas não possam ser aplicadas a mulheres solteiras ou a casais homossexuais, tendo apenas como alvo 'pessoas casadas que não se encontrem separadas judicialmente de pessoas e bens ou separadas de facto' ou às que, 'sendo de sexo diferente, vivam em condições análogas às dos cônjuges há pelo menos dois anos' (Faria, 11.07.2008). Esta situação implica que haja médicos portugueses a trabalhar com clínicas espanholas de modo a contornar os obstáculos jurídicos em Portugal. Por exemplo, o director do ICBAS, Mário Sousa, admite o seguinte: 'Faço inseminação com dador em Espanha, elas vivem cá a gravidez e depois mando-as de novo a Espanha para ter o bebé, que fica com naturalidade espanhola, porque cá é proibido ser filho de pai incógnito' (Faria, 11.07.2008).

\section{FERTILIZAÇÃo IN VITRO}

A fertilização in vitro (FIV) diz respeito a uma técnica mediante a qual se fertiliza um ovócito com um espermatozóide numa proveta, sendo o embrião resultante posteriormente implantado no útero de uma mulher, usualmente a progenitora. Louise Joy Brown foi o primeiro 'bebé proveta', nascida em 1978 no Reino Unido, havendo hoje mais de três milhões de bebés-proveta concebidos por FIV a nível internacional. A FIV é, efectivamente, uma técnica de Procriação Medicamente Assistida considerada banal na actualidade, sendo que, segundo o New York Times, 'quase todos os norte-americanos conhecem hoje uma família que poderia não ter existido sem a FIV ou uma das suas 
variantes' (Gerschenfeld, 25.07.2008). No entanto, na época em que Louise foi concebida, a FIV provocou reacções violentas, particularmente de sectores religiosos, que acusavam os médicos de 'brincar aos deuses' (Gerschenfeld, 25.07.2008). A notícia refere ainda que Louise Brown é mãe de um menino, Cameron. Entre parênteses, é-nos transmitido que Cameron foi concebido naturalmente, o que ajuda a dissipar quaisquer dúvidas que houvesse relativamente à capacidade de alguém concebido por um método semelhante à ficção científica se reproduzir de modo 'natural'. Curiosamente, a capacidade de engravidar sem recorrer a técnicas de Procriação Medicamente Assistida serve de bitola para avaliar da 'humanidade' de um ser - Louise Brown — criado por essas mesmas técnicas.

As vozes que se levantaram contra a FIV há trinta anos, continuam activas no que toca à problematização ética decorrente da aplicação de técnicas de reprodução assistida. De acordo com o documento Dignitas Personae, datado de 8 de Setembro de 2008 e divulgado pela Congregação para a Doutrina da Fé, a procriação medicamente assistida e a terapia genética são apontadas como eticamente condenáveis. $\mathrm{O}$ documento fundamenta-se no 'princípio de respeito incondicional pela vida humana (desde a concepção até uma morte natural) e da criação de novas vidas no contexto do matrimónio, "fruto do acto conjugal específico do amor entre os esposos"' (Freitas, 13.12.2008). A tentativa de se controlar processos naturais por intervenção humana é condenada com base na ideia de que 'o homem pretende substituir-se ao Criador' (Freitas, 13.12.2008). O especialista em genética, Alberto Barros, católico confesso, expressa a sua vergonha pela posição da Igreja, alegando o seguinte: 'Acredito na criação divina e na perfeição da criação, mas sei que a natureza assumiu uma autonomia que levou a desvios, que são patologias. A obrigação do médico é lutar contra isso' (Freitas, 13.12.2008) Ou seja, o discurso médico considera a infertilidade como um desvio de um percurso natural, o da fertilidade. Tem como objectivo substituir-se à natureza, imitando-a. Curiosamente, apesar do discurso médico se opor ao do Vaticano, ambos presumem a natureza como um bem supremo, algo no qual não se deve interferir no caso da perspectiva Católica, e algo que se pretende simular no caso do discurso médico.

Outro tema recorrente na cobertura jornalística da FIV diz respeito ao facto de ser considerada um tratamento claramente dispendioso, sendo que as listas de espera nos hospitais públicos são intermináveis para os cerca de 500 mil casais portugueses que sofrem de infertilidade. A promessa, datada de Novembro de 2007, de que o Estado iria comparticipar os tratamentos de Procriação Medicamente Assistida em clínicas privadas aind não se concretizou, o que agravou a lista de espera existente nos hospitais públicos (Público, 13.10.2008). Os tratamentos de fertilidade em clínicas privadas são apontados como responsáveis pelo aumento de gravidezes gemelares, comportando um risco particularmente elevado. Esta situação prende-se com o facto de os casais pretenderem rentabilizar o investimento, que ronda cerca de quatro mil euros por ciclo de tratamento, pressionando os médicos no sentido de fazer transferência de mais de dois embriões de cada vez de modo a maximizar a oportunidade de engravidar através de uma técnica que tem um índice de êxito de 30 por cento. Silva Carvalho, presidente 
da Sociedade Portuguesa de Medicina de Reprodução, alega que a comparticipação do Estado será a melhor forma de controlar o número de embriões transferido em cada ciclo de tratamento e de 'combater as gravidezes múltiplas' daí decorrentes ao aligeirar o 'esforço financeiro das famílias' (Gomes, 07.09.2008). O Estado surge assim como garante de protecção da saúde dos cidadãos, assegurando que as técnicas de reprodução assistida praticadas em clínicas privadas não constituam apenas 'transacções comerciais' destituídas de um sentido de responsabilidade. Por outras palavras, a comparticipação do Estado vai permitir às técnicas de reprodução assistida uma crescente simulação daquilo que acontece num processo de reprodução natural, a diminuição da probabilidade de gravidezes gemelares, o que é alegadamente mais benéfico para a saúde da mãe e do feto.

\section{BARRIgAS DE ALUgUeR}

Em casos em que a infertilidade se prende com a incapacidade de se produzir gâmetas (ovócitos ou espermatozóides), os casais podem recorrer a barrigas de aluguer ou então a doações de ovócitos ou de esperma. Na cobertura jornalística do tema das barrigas de aluguer, enfatiza-se a componente do legado biológico, sendo que a maternidade e paternidade estão associadas a quem doou os seus gâmetas (espermatozóides ou ovócitos) para gerar um embrião, embrião esse que será posteriormente implantado numa barriga de aluguer. Esta técnica desconstrói o conceito de maternidade biológica investindo-o de uma conotação acima de tudo social na medida em que a 'barriga de aluguer' é uma mera transportadora do embrião implantado, passando a 'mãe' a ser outra que não a que dá à luz.

Esta técnica é referida como possibilitando aos casais homossexuais terem um filho biológico. No entanto, tanto no caso dos gays como das lésbicas, 'a criança só pode ser herdeira biológica de um dos dois pais - ou mães: do que contribuiu com o seu esperma ou ovócito para a gerar' (Gerschenfeld, 25.02.2008). A criação de espermatozóides e ovócitos a partir de células estaminais embrionárias de animais ou de humanos, células essas que podem dar origem a qualquer tecido do organismo', permitiria aos casais homossexuais 'doar células de pele para gerar ovócitos que seriam fecundados pelo esperma do parceiro e implantados numa barriga de aluguer' (Gerschenfeld, 25.02.2008). Para Davor Solter, biólogo do desenvolvimento do Instituto de Biologia Médica de Singapura, esta possibilidade 'significa que qualquer pessoa poderia ter filhos: as crianças recém-nascidas poderiam ter filhos e as pessoas centenárias poderiam ter filhos. Isto poderia facilmente acontecer nos próximos 30 anos.' Neste cenário futurista, também se adivinha o aparecimento de 'placentas artificiais', em que um feto possa 'flutuar livremente num fluido, com o cordão umbilical ligado a uma máquina' (Solter, in Gerschenfeld, 25.07.2008). A criação de úteros artificiais constituem outra possibilidade com implicações significativas no que toca ao aumento de taxa de sobrevivência de bebés prematuros, Segundo o especialista em Ética da Universidade Estadual do Oklahoma, Scott Gelfand, 'Actualmente, os bebés só podem sobreviver fora do útero 
a partir das 22 semanas, mas no futuro isso poderá ser alargado para aqueles que têm apenas 12 semanas. (...) Se um útero artificial for desenvolvido, o governo poderia vir a adoptar uma lei que obrigasse as pessoas que interrompem uma gravidez a colocar os fetos num desses úteros' (Gerschenfeld, 25.07.2008). Tal situação comportaria o risco de que o número de abortos nos EUA - mais de um milhão — se transformasse no número de bebés disponível para adopção nos EUA. Gelfand utiliza este argumento para enfatizar que entre duas alternativas que ameaçam interromper o livre curso da natureza - o aborto por um lado e a criação de um útero artificial por outro lado — o aborto é incomensuravelmente mais aceitável.

Problemas jurídicos também podem ser gerados por se recorrer a barrigas de aluguer. Um exemplo referido no corpus analisado diz respeito a um casal japonês que pagou a uma 'barriga de aluguer' indiana para ser implantada com o seu embrião, gerado por fertilização in vitro, resultando no nascimento de uma menina, Manji. O conflito jurídico prende-se com o facto de o casal se ter entretanto divorciado, sendo a criança rejeitada pela barriga de aluguer bem como pela mãe biológica. Apesar de o pai, Ikufumi Yamada, querer assumir a custódia de Manji, esta foi-lhe impedida por a lei indiana não permitir a entrega de crianças a homens solteiros. Por isso mesmo, o futuro de Manji permanecia incerto à data da publicação desta notícia, sendo a mãe de Ikufumi Yamada citada ao afirmar que o 'filho "ama muito a sua filha" e ... como avó, está bastante desgostosa. "Dedico toda a minha afeição a essa menina e choro o tempo todo" (Público, 08.08.2008).' O artigo termina com uma constatação de que as barrigas de aluguer constituem um fenómeno comum na Índia, podendo as mulheres carenciadas ganhar entre cinco a 15 mil dólares com este 'negócio'.

O episódio relatado desconstrói o conceito de maternidade pelo facto de o pai ser claramente representado como zelando pela filha de modo mais responsável do que as duas mulheres envolvidas na gestação da criança, quer a mãe biológica quer a barriga de aluguer. É como se estas mulheres rejeitassem o produto de uma técnica que lhes foi virilmente imposta, a mãe biológica numa altura em que ainda estava casada e a barriga de aluguer por cumprir uma tarefa que integra o circuito do capitalismo 'reprodutivo'. $\mathrm{O}$ facto de as barrigas de aluguer serem alegadamente frequentes na Índia reaviva um cenário de neo-colonialismo tecnológico em que casais do Atlântico Norte recorrem a estes serviços em países em vias de desenvolvimento (Deonandan, Green \& van Beinum, 2012, p. 742), deixando-se o corpo da mulher nativa invadir por tecnologias que lhe são alheias com o intuito de assegurar subsistência económica.

Recorde-se que o recurso a 'úteros de substituição' nos EUA custa uma média de 60 mil euros, sendo tal 'tratamento' proibido na Europa. Há médicos, no entanto, que sustentam que a legislação europeia deveria apoiar a disponibilização de úteros de substituição em determinados casos. O fundador do Centro de Genética da Reprodução, Alberto Barros, por exemplo, considera que esse recurso deve 'poder ser equacionado em casos como o da mãe que disponibiliza o seu útero para que o embrião da filha possa ser gerado.' Na sua opinião, tal constitui 'um acto de amor e generosidade que pode ser enquadrado no âmbito médico das técnicas' (Faria, 11.07.2008). O discurso médico aqui 
revela claramente uma compreensão tradicionalista da maternidade, privilegiando uma concepção biológica que enfatiza uma ligação quase fusional entre mãe e filha: enquanto se condena o recurso a um útero de substituição anónimo, aceita-se que uma mãe possa doar o seu útero à filha com o propósito de gerar uma neta. Esta promiscuidade entre categorias 'avó', 'mãe' e 'neta' sustenta-se na ideia de um património genético comum, uma cadeia de transmissão de informação genética que integra o domínio da 'natureza'. O discurso médico que concebe a maternidade em termos biológicos é aqui apoiado pelo discurso cultural da maternidade enquanto acto supremo de 'amor e generosidade', traduzido pela doação do útero da mãe à filha, um gesto que se distancia do espírito de transacção comercial inerente às barrigas de aluguer.

\section{DoAÇÃo DE ESPERMATOZÓIDES E OVÓCITOS}

A cobertura noticiosa deste tema realça o direito dos filhos conhecerem as 'origens genéticas' caso os pais tenham recorrido à doação de espermatozóides e ovócitos, de modo a que possa adquirir 'mais conhecimento sobre a sua identidade' (Gomes, 25.02.2009). No Reino Unido, a lei contempla o direito de todas as crianças nascidas depois de Abril de 2005 a conhecerem os seus pais biológicos ao atingirem os 18 anos (Gerschenfeld, 02.07.2008). A legislação em vigor em Portugal preserva o anonimato do dador, 'salvo se este o permitir expressamente em processo de obtenção de informação sobre existência de eventual impedimento para casamento (por receio de incesto)' (Gomes, 25.02.2009). O receio dos pais de que possam ser substituídos pelos dadores enquanto 'figura parental' faz com que exista uma maior receptividade relativamente ao conhecimento dos irmãos do que dos pais biológicos. Num estudo realizado pelo Centro de Pesquisa Familiar da Universidade de Cambridge, refere-se que a maioria de mulheres que recorre à doação de espermatozóides para engravidar é constituída por 'mães solteiras (39 por cento), casais de lésbicas ( 35 por cento) e uma minoria de casais heterossexuais (21 por cento)' (Gomes, 25.02.2009).

À medida que a doação de ovócitos e espermatozóides se vai tornando cada vez mais comum, assiste-se a uma infiltração cada vez maior deste tema no espaço público. A título de exemplo, Linda e Richard Weeks, um casal britânico na casa dos 50, colocou um anúncio publicitário na rede de transportes públicos londrina em 2008, apelando à doação de ovócitos por parte de uma mulher com 36 anos ou menos. O jornal Times, citado pela notícia do Público, atribui o resultado 'espectacular', rondando as 96 respostas, ao 'impacto do anúncio junto dos media' (Gerschenfeld, 02.07.2008). No entanto, ao tomar conhecimento da gratuidade de todo o processo, que implicaria um tratamento hormonal que culmina com a recolha de ovócitos num bloco operatório mediante anestesia geral, apenas uma mulher aceitou levar o tratamento até ao fim.

Este caso não só é importante por demonstrar o modo como estratégias mediáticas podem ser utilizadas a favor das PMA, como também por sublinhar que a dissociação deste tipo de tratamentos do circuito capitalista de transacções comerciais pode efectivamente traduzir-se na incapacidade de levar tais técnicas até ao fim. Efectivamente, 'a 
gratuidade das doações' é considerada, no Reino Unido, 'como a principal responsável pela escassez de ovócitos para doação' (Gerschenfeld, 02.07.2008). Para além disso, este caso volta a revolucionar o conceito tradicional de maternidade na medida em que a própria Linda Weeks reconhece que a filha - Katy — nascida da doação de ovócitos foi resultado de um acto de generosidade da parte de uma mulher que lhe ofereceu 'o dom da vida': 'Seja qual for o destino de Katy, será graças a nós os três' (Gerschenfeld, O2.07.2008). Os progenitores passam assim de dois a três, sendo o conceito de maternidade — habitualmente associado ao poder do 'dom da vida' — aqui repartido entre as vertentes biológica por um lado e social por outro lado.

\section{5. ÉTICA E PMA}

Um tema particularmente recorrente no que toca às técnicas de reprodução assistida diz respeito à problematização ética relacionada com o destino dos embriões. Por vezes, nem todos os embriões são usados no caso de se recorrer a tratamentos de fertilidade. Com a regulamentação de uma lei portuguesa que prevê o destino de embriões excendentários, impôs-se uma escolha aos pacientes que se submeteram a tratamentos sobre o que fazer aos seus embriões congelados: se não tiverem sido utilizados pelo casal para novas gravidezes no prazo de três anos, 'ou os dão para investigação ou doam-nos para outros casais com problemas', não sendo a destruição de embriões contemplada pela lei portuguesa (Gomes, 25.05.2008). Alguns estudos internacionais citados pela notícia referem que há uma clara reticência da parte dos casais em doar os seus embriões excedentários a outros casais com problemas de fertilidade. Tal ideia comprova o facto de a maternidade e paternidade serem compreendidas, acima de tudo, biologicamente, sendo que a partilha de um património genético pode ser considerado como uma invasão de identidade e individualidade próprias. Dissocia-se assim a componente social da parentalidade — da criação de um filho — da componente biológica, dando-se clara primazia à natureza por oposição à cultura no tratamento destas questões.

A cobertura jornalística analisada aponta o Reino Unido como estando na dianteira da investigação ao nível da embriologia, tomando a iniciativa de legalizar a geração de embriões híbridos humano-animal. Estes embriões, denominados 'cíbridos' (híbridos citoplásmicos), são constituídos por 99,9 por cento de ADN humano e 0,1 por cento de ADN animal, evitando 'o recurso à doação de ovócitos por mulheres para fins de investigação científica' (Gerschenfeld, 25.05.2008). O objectivo final dos cientistas é o de extrair e clonar células estaminais embrionárias dos cíbridos, utilizando-as com o intuito de desenvolver terapias inovadoras no combate a doenças degenerativas. A notícia refere que a aprovação desta lei foi controversa, tendo grupos religiosos e pró-vida apontado o risco de 'cenários apocalípticos de ficção científica' decorrentes de manobras de investigadores que 'passariam a brincar impunemente aos Frankensteins' (Gerschenfeld, 25.05.2008). Efectivamente, qualquer intervenção em processos naturais é representada como antagónica ao pensamento religioso, particularmente o católico, que pressupõe a natureza como tendo um fundamento ético no qual o homem não 
deve intervir. Os deputados católicos trabalhistas são descritos como protagonizando uma cisão com o Executivo de Gordon Brown, ao exigir liberdade de voto nesta matéria (Machado, 24.03.2008).

A intervenção de cientistas em processos naturais também evoca, no imaginário do cidadão comum, fantasmas de eugenia. Um dos receios que surge nas notícias que focam a doação de gâmetas está relacionado com a possibilidade de se escolher 'bebés à la carte', com características físicas específicas. Enquanto as técnicas de diagnóstico genético permitem eliminar determinadas doenças genéticas, tal como a doença dos pezinhos, essas mesmas técnicas podem ser utilizadas para escolher cor de olhos, cor de cabelo e o sexo do feto. A clínica norte-americana Fertility Institutes, cujo serviço de 'bebés à la carte' foi suspenso por causar demasiada polémica, disponibiliza uma base de dadores de espermatozóides e de ovócitos com características diversificadas: 'a dadora 110484 é branca, tem olhos verdes, o cabelo é castanho ondulado, estuda Direito e joga ténis; já a 032284 é negra, tem cabelo encaracolado, estuda Arquitectura e faz ciclismo' (Gomes, 06.03.2009). Curiosamente, tal como se supõe que o feto possa herdar de modo directo as características físicas de determinada dadora, também se pressupõe que os hobbies e inclinações dessa mesma dadora sejam passados de modo natural para o bebé. Silva Carvalho, presidente da Sociedade Portuguesa de Medicina da Reprodução, afirma, neste contexto, que se seleccionam 'dadores para estarem de acordo com o fenótipo [aspecto físico] do homem ou da mulher, para ser um filho parecido com os pais. Não se ia escolher um dador de raça negra para pais brancos'. Embora este médico não esteja a referir-se à selecção de características de modo a produzir 'um bebé bonito', ele nem por isso deixa de parte o discurso que valoriza a natureza como ligada à parentalidade: escolhe-se um dador branco para pais brancos de modo a simular aquilo que é natural. Ou seja, as tecnologias reprodutivas interferem na natureza quando a natureza falha, isto é, quando existe alguma 'patologia' que se traduz sob a forma de infertilidade. No entanto, o artifício da intervenção humana num processo dito natural deve ser encoberto, simulando a natureza o melhor possível. Qualquer intervenção que fracassasse nessa simulação chamaria a atenção para o facto de a parentalidade não ser um processo totalmente natural. E aí a autenticidade da parentalidade correria o risco de ser posta em causa.

\section{Conclusão}

O conceito tradicional de maternidade assume que as mães estabelecem laços afectivos permanentes com os seus filhos devido às experiências de gravidez, parto e amamentação (Rich, 1986). Ao enfatizar a separação entre o social e o biológico, as técnicas de procriação medicamente assistida possibilitam a valorização de uma concepção social e não biológica da maternidade (Andrews, 1989). No entanto, testemunhámos, ao longo dos casos jornalísticos analisados, que o discurso médico procura encobrir essa valorização do social ao enquadrá-la no âmbito de uma concepção biológica da maternidade. Esse enquadramento baseia-se na tentativa de as técnicas de reprodução 
assistida procurarem simular a natureza tal como ela é. Qualquer desvio da natureza, correspondendo esta última a uma espécie de forma ideal platónica, é concebido como um desvio patológico a 'curar'.

M. E. Young considera que as novas tecnologias de reprodução assistida são particularmente controversas porque, ao possibilitar novas relações, põem em causa velhos padrões conceptuais relativos à família. Somos assim obrigados a repensar o significado das relações maternais se não quisermos simplesmente encaixar à força novas configurações sob modelos já existentes (Young, 1995, p. 261). Esta tentativa de se redefinir a maternidade não é consensual, mesmo no seio do pensamento feminista. Se por um lado há feministas que celebram a primazia do social sobre o biológico representado pelas técnicas de Procriação Medicamente Assistida, outras celebram 'a santidade da vinculação biológica entre mãe e filho' (Rapping, 1990, p. 541). Firestone (1971), por exemplo, considerava que a reprodução biológica exterior ao útero libertaria a mulher dos constrangimentos da maternidade e, mais recentemente, Singer e Wells (1983) apontavam o crescimento do feto fora do útero como conducente a uma maior igualdade sexual. No entanto, um número crescente de feministas está a contestar as novas técnicas de reprodução assistida por estas alegadamente comportarem riscos para a saúde da mulher, ameaçarem os seus direitos e escolhas e serem demasiado dispendiosas (Moss, 1988, p. 40).

Em termos jornalísticos, parece-nos que o Público tem alguma dificuldade em resistir à tentação de inserir à força as novas configurações de maternidade decorrentes do recurso a técnicas de Procriação Medicamente Assistida sob modelos tradicionais. Ao privilegiar o discurso médico na interpretação hegemónica dos riscos e benefícios dessas técnicas de reprodução, o Público veicula uma concepção da maternidade que privilegia claramente o biológico em detrimento do social: a transmissão de um património genético é tida como o factor mais importante no que toca à definição de maternidade, sendo que se sobrepõe à dimensão de 'educar/criar um filho'. Conforme sugere Stanworth (1997, p. 485), "tal abordagem implica que qualquer processo "menos" natural desde a concepção até ao nascimento representa a degradação da própria maternidade.' Assim, o conceito de maternidade articulado pelo discurso médico é definido biologicamente, assumindo-se que todas as mulheres se relacionam com a experiência da reprodução do mesmo modo, independentemente de factores de diferenciação tais como a idade, saúde, classe social, nacionalidade, entre outros.

\section{REFERÊNCIAS}

Andrews, L. (1989). Alternative modes of reproduction. In S. Cohen; N. Taub (Org.), Reproductive Laws in the 1990's (pp. 361-403). Clifton, Nova Jérsia: Humana Press.

Campos, A. (2008, 13 de Outubro). 'Lista de espera para tratamentos de infertilidade está a aumentar.' Público. http://www.publico.pt/sociedade/noticia/ lista-de-espera-para-tratamentos-de-infertilidade-esta-a-aumentar-1345809. 
Deonandan, R; Green, S. \& van Beinum, A (2012). Ethical concerns for maternal surrogacy and reproductive tourism. Journal of Medical Ethics, 38: 742-745.

Faria, N. (2008, 7 de Novembro). Ser mãe aos 70 é uma vitória mas pode ser falta de bom senso.' Público. http://www.publico.pt/temas/jornal/ ser-mae-aos-70-e-uma-vitoria-mas-pode-ser-falta-de-bom-senso-268339

Firestone, S.(1971). The dialectic of sex. Nova Iorque: Bantam Books.

Freitas, A. C. (2008, 13 de Dezembro). Vaticano considera fertilização artificial e terapia genética moralmente inaceitáveis. Público. http://www.publico.pt/mundo/jornal/ vaticano-considera-fertilizacao-artificial--e-terapia-genetica-moralmente-inaceitaveis-287824

Gerschenfeld, A. (2008, 25 de Julho). Há 30 anos tudo isto parecia ficção científica. Público. http://www. publico.pt/temas/jornal/ha-3o-anos-tudo-isto-parecia-ficcao-cientifica-270024

Gerschenfeld, A. (2008, 2 de Julho). 50 autocarros chamados desejo de mãe. Público., p. Ou pp? http://www. publico.pt/temas/jornal/50-autocarros-chamados-desejo-de-mae-267208

Gerschenfeld, A. (2008, 25 de Maio). Britânicos entraram oficialmente na era da medicina do século XXI. Público. http://www.publico.pt/destaque/jornal/ britanicos-entraram-oficialmente-na-era-da-medicina-do-seculo-xxi-262383

Gerschenfeld, A. (2008, 25 de Fevereiro). Fertilização cruzada. Público. http://www.publico.pt/temas/jornal/ fertilizacao-cruzada-250642

Gomes, C. (2009, 6 de Março). Ainda não estamos prontos para bebés à la carte.' Público. http://www. publico.pt/temas/jornal/ainda-nao-estamos-prontos-para-bebes-a-la-carte-298094

Gomes, C. (2009, 25 de Fevereiro). Famílias que recorrem a doação de espermatozóides e ovócitos querem que filhos conheçam as suas origens. Público. http://www.publico.pt/mundo/jornal/familiasque-recorrem-a-doacao-de-espermatozoides--e-ovocitos-querem-que-filhos-conhecam-as-suasorigens-296918

Gomes, C. (2008, 7 de Setembro). Mais gémeos que nunca devido a tratamentos de infertilidade. Público. http://www.publico.pt/portugal/jornal/ mais-gemeos-que-nunca-devido--a-tratamentos--de-infertilidade-275058

Gomes, C. (2008, 25 de Maio). Casais portugueses terão de escolher destino dos embriões. Público. http:// www.publico.pt/destaque/jornal/casais-portugueses-terao-de-escolher-destino-dos-embrioes-262381

Machado, A. (2008, 24 de Março). Reforma da lei sobre embriologia divide trabalhistas britânicos. Público. http://www.publico.pt/mundo/jornal/ reforma-da-lei-sobre-embriologia-divide-trabalhistas-britanicos-254297

Moss, K. E. (1988). New reproductive technologies: Concerns of feminists and researchers. Affilia, 3 (4): 38-50.

Público (2008, 8 de Agosto). Bebé japonês de mãe de aluguer indiana ficou órfão devido ao divórcio dos pais.' http://www.publico.pt/mundo/jornal/ bebe-japones-de-mae-de-aluguer-indiana-ficou-orfao-devido-ao-divorcio-dos-pais-271671

Rapping, E. (1990). The future of motherhood: some unfashionably visionary thoughts. In K. Hansen; I. Philipson (Org.), Women, Class, and the Feminist Imagination: A Socialist-Feminist Reader (pp. 537-548). Filadélfia: Temple University Press.

Rich, A. (1986). Of woman born: motherhood as experience and institution. Nova lorque: Norton. 
Silva Costa, S. (2008, 8 de Março). A ternura de ser mãe aos 40. Público. http://www.publico.pt/temas/ jornal/a-ternura--de-ser-mae--aos-40-252334

Singer, P.; Wells, D. (1983). The reproductive revolution: New ways of making babies. Nova lorque: Oxford University Press.

Stanworth, M. (1997). Reproductive technologies: Tampering with nature?. In S. Kemp; J. Squires (Org.), Feminisms (pp. 482-87). Oxford: Oxford University Press.

Young, M. E. (1995). Reproductive technologies and the law: norplant and the bad mother. In L. Mclntyre; M. B. Sussman (Org.), Families and Law (pp. 259-81). Nova lorque: Haworth.

Cláudia Álvares foi eleita presidente da European Communication Research and Education Association (ECREA) em Outubro de 2012. No âmbito da iniciativa da Fundação Europeia para a Ciência (ESF) intitulada 'Forward Look in Media Studies', concentrou-se no tema da participação política, o que conduziu ao artigo da Revista Javnost denominado 'Political Participation in an Age of Mediatization: Toward a New Research Agenda' (em co-autoria, 2013). Entre as suas publicações, encontram-se os seguintes livros: Media in Europe: New Questions for Research and Policy (co-autoria, 2014), Gendered Transformations: Theory and Practices on Gender and Media (organização conjunta, 2010), Teorias e Práticas dos Media: Situando o Local no Global (organização conjunta, 2010), Representing Culture: Essays on Identity, Visuality and Technology (organização individual, 2008), Humanism after Colonialism (autoria individual, 2006). Investigadora principal, em anos recentes, de três projectos de investigação financiados pela Fundação Portuguesa para a Ciência e Tecnologia, tem regularmente integrado os painéis quer da Agência Portuguesa para a Avaliação do Ensino Superior ( $\left.A_{3} E s\right)$, desde 2013, quer os do European Research Council (ERC) Starting Grant Calls in the Social Sciences and the Humanities, desde 2014. Cláudia Álvares doutorou-se pela Goldsmith's College, University of London, sendo correntemente Professora Associada da Universidade Lusófona (Lisboa, Portugal).

E-mail:p1693@ulusofona.pt

Universidade Lusófona Campo Grande 376, 1749-024, Lisboa, Portugal 